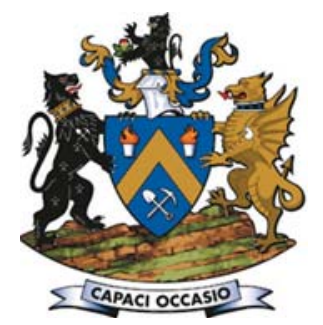

\title{
Deformation behaviour of aluminium low-micron MMCs and MMNCs at warm working temperatures $\left(0.3-0.5 \mathrm{~T}_{\mathrm{m}}\right)$
}

\author{
by Z. Gxowa*†‡, L.H. Chown ${ }^{\dagger \neq}$, G. Govender* and U. Curle*
}

\section{Synopsis}

This work evaluates the deformation behaviour, at warm working temperatures, of green particle-reinforced aluminium composites produced by powder blending in a high-energy ball mill. The work focuses on metal matrix composites (MMCs) based on the 2124-Al alloy, reinforced with 10 or $15 \mathrm{vol} \% \mathrm{SiC}$ and metal matrix nanocomposites (MMNCs) based on the 2124-Al alloy, reinforced with 5 or $10 \mathrm{vol} . \% \mathrm{Al}_{2} \mathrm{O}_{3}$. Three batches for each powder were blended and powder properties such as particle size distribution (PSD) and shape were consistent after blending. It was observed that a more uniform distribution of the reinforcement phase in the aluminium alloy matrix was achieved in $2124-\mathrm{Al} / \mathrm{Al}_{2} \mathrm{O}_{3}$ than in 2124$\mathrm{Al} / \mathrm{SiC}$ composites. The powders (unreinforced 2124- $\mathrm{Al}$ and blended) were initially over-aged at $350^{\circ} \mathrm{C}$ for 2 hours to reverse any natural ageing that may have occurred prior to use. The over-ageing was incorporated to improve compressibility of the powders with the aim of achieving green compacts with higher integrity. Uniaxial compression tests performed at ambient temperature on a Gleeble ${ }^{\circledR} 3500$ thermomechanical simulator were unsuccessful as the green compacts fragmented. Engineering stress-strain curves showed that green compacts of unreinforced 2124-Al, 10\%SiC MMC and $5 \% \mathrm{Al}_{2} \mathrm{O}_{3} \mathrm{MMNC}$ deformed in a similar manner at ambient temperature and had the same compressive fracture stress of approximately $170 \mathrm{MPa}$. When the deformation temperature was increased from ambient to warm working temperatures $\left(170-280^{\circ} \mathrm{C}\right)$ it was observed that electrical resistance heating (the heating mode of the Gleeble ${ }^{\circledR}$ ) of unreinforced $\mathrm{Al}$ alloy, MMC and MMNC green compacts did not occur. This was attributed to the high electrical conductivity of aluminium, which resulted in poor heat generation due to the low electrical resistance in the samples. It was presumed that the small sample size $(d=8 \mathrm{~mm}, h=12 \mathrm{~mm})$ also caused rapid heat loss. After further experimentation, the green compacts were heated successfully by insulating the samples to retain heat. It was found that at $280^{\circ} \mathrm{C}$, increasing the soaking time from 6 to 20 minutes decreased flow stress and improved plastic flow in the $2124-\mathrm{Al} / 10 \% \mathrm{SiC}$ green compact.

\section{Keywords}

metal matrix composites, metal matrix nanocomposites, 2124-Al alloy.

\section{Introduction}

The automotive and aerospace industries have been interested in metal matrix composites (MMCs) and metal matrix nanocomposites (MMNCs) due to the growing demand for lightweight, high-performance materials (Mazen and Emara, 2004). MMCs and MMNCs have been considered as replacements for conventional metals and alloys because they have higher stability at elevated temperatures, good strength-to-mass ratios and superior wear resistance, along with high stiffness and strength (Zhou et al., 1999).
The mechanical properties of composite products are influenced mainly by the distribution of reinforcing particles in the matrix and the strength of the interfacial bonds between reinforcing particles and the matrix (Liang et al., 1992). The ideal composite has an even distribution of the reinforcement phase throughout the matrix (Ferry, 2005), but generating this is a challenge when fabricating both MMCs and MMNCs. In MMCs, the micrometre-sized reinforcing particles tend to settle on the grain boundaries and in MMNCs the nano-sized reinforcing particles form agglomerates (Borgonovo and Apelian, 2011; Casati and Vedani, 2014).

Secondary deformation processes such as extrusion, forging, rolling and drawing may be used to improve the reinforcing particle distribution, thereby enhancing mechanical properties such as hardness and strength (Hirianiah et al., 2012). These deformation processes are usually carried out at high temperatures since more deformation can be achieved due to the increased plastic flow (Saravanan and Senthilvelan, 2015). However, operating at high temperatures has the disadvantages of high energy costs, reduced equipment and tool life, poor surface finish and low dimensional accuracy (Rajput, 2007). These disadvantages mean that hotworked MMC and MMNC components are expensive and thus are unattractive to industry.

* Materials Science and Manufacturing, Council for Scientific and Industrial Research (CSIR).

+ School of Chemical and Metallurgical Engineering, University of the Witwatersrand, Johannesburg, South Africa.

₹ DST-NRF Centre of Excellence in Strong Materials, hosted by University of the Witwatersrand, Johannesburg, South Africa.

(c) The Southern African Institute of Mining and Metallurgy, 2016. ISSN 2225-6253. This paper was first presented at the AMI Ferrous and Base Metals Development Network Conference 2016 19-21 October 2016, Southern Sun Elangeni Maharani, KwaZulu-Natal, South Africa. 


\section{Deformation behaviour of aluminium low-micron MMCs and MMNCs}

Warm working has been shown to have some advantages over both cold and hot working (Rao et al., 1999). Advantages of warm working over cold working include (Cavaliere, 2002):

> Less strain hardening - fewer annealing operations

> Increased plastic flow - lower loads are required

> Higher metal ductility.

Warm working has lower processing costs than hot working due to the lower energy requirement, longer equipment and tool life and better dimensional accuracy and surface finish (Cavaliere, 2002). Operating at warm working temperatures may thus decrease processing costs while still producing high-quality products (Jensrud, 1998).

In this work, the deformation behaviour, at warm working temperatures, of particle-reinforced aluminium composites produced by powder blending in a high-energy ball mill was evaluated through uniaxial compression tests performed on a Gleeble ${ }^{\circledR} 300$ thermomechanical simulator.

\section{Experimental procedure}

A Simoloyer CM-01 ${ }^{\circledR} 2 \mathrm{~L}$ horizontal high-energy ball mill was used to blend 2124 aluminium alloy $(45-90 \mu \mathrm{m}$ ) powder (the matrix material) with reinforcing powders to form:

> Low-micron aluminium metal matrix composites with 10 or $15 \mathrm{vol} . \% \mathrm{SiC}(1-10 \mu \mathrm{m})$ as the low-micron reinforcement

- Metal matrix nanocomposites with 5 or $10 \mathrm{vol} . \% \mathrm{Al}_{2} \mathrm{O}_{3}$ (40-70nm) as the nano-sized reinforcing phase.

Three batches of 2124 aluminium alloy powder with $\mathrm{Al}_{2} \mathrm{O}_{3}$ (MMNC) and three with $\mathrm{SiC}$ (MMC) powder were blended to assess the consistency of blending. The powders were characterized by particle size and shape analysis using a Microtrac Bluewave ${ }^{\circledR}$ and were visually assessed by scanning electron microscopy (SEM) on a JEOL JSM 6510. The unreinforced aluminium alloy powder and the blended powders were then cold-compacted, i.e. at ambient temperature, into cylindrical green compacts with a diameter of $8 \mathrm{~mm}$ and height of $12 \mathrm{~mm}$ in preparation for the uniaxial compression tests.

The initial cold compaction trials of both the unreinforced aluminium alloy powder and blended powders were challenging as the green compacts fractured into horizontal slices. This was attributed to natural ageing of the $\mathrm{Al}$ alloy powder due to long-term storage. The powders (unreinforced 2124- $\mathrm{Al}$ and blended) were then over-aged at $350^{\circ} \mathrm{C}$ for 2 hours, which improved their compressibility and resulted in green compacts with better consolidation and no surface cracks. The deformation behaviour of the unreinforced 2124 aluminium alloy, $\mathrm{MMC}$ and $\mathrm{MMNC}$ green compacts was evaluated by performing uniaxial compression tests on a Gleeble $3500 \otimes$ thermomechanical simulator at approximately $25^{\circ} \mathrm{C}$ and $280^{\circ} \mathrm{C}$, a total strain of 0.1 and a strain rate of $0.01 \mathrm{~s}^{-1}$. The green compacts were soaked for 6 minutes before compression. The soaking time was then increased to 20 minutes for the MMC green compact with $10 \mathrm{vol}$ \% SiC to evaluate the effect of soaking time on deformation behaviour.

\section{Results and discussion}

Three batches (referred to as batch 1, 2 and 3) of each powder were blended, which helped to assess if the properties that were obtained after blending were consistent.

\section{Blending}

5 vol. $\% \mathrm{Al}_{2} \mathrm{O}_{3}$

SEM micrographs of MMNC blended powders with 5 vol.\% $\mathrm{Al}_{2} \mathrm{O}_{3}$ from three batches at 500x magnification are shown in Figure 1. From these images it can be observed that there are lighter, finer $\mathrm{Al}_{2} \mathrm{O}_{3}$ particles on the surface of the coarser, spherical 2124-Al alloy powder particles. The three batches have a relatively uniform distribution of $\mathrm{Al}_{2} \mathrm{O}_{3}$ particles on the aluminium alloy particles. Figure 1a shows that some of the aluminium alloy particles have changed shape and some have fractured into smaller particles. The change in particle shape can be attributed to plastic deformation that occurred during blending.

$10 \mathrm{vol} . \% \mathrm{Al}_{2} \mathrm{O}_{3}$

Figure 2 shows a similarly uniform distribution of $\mathrm{Al}_{2} \mathrm{O}_{3}$ nano-sized particles on the 2124-Al powder particles, despite the 5 to 10 vol.\% increase in $\mathrm{Al}_{2} \mathrm{O}_{3}$. This finding contradicts results found in liquid-state processing, where Borgonovo and Apelian (2011) found that the tendency of nanoparticles to form agglomerates increased as their volume fraction in the matrix increased. The even distribution found in this work (Figure 2) can be attributed to good blending parameters, as well as the fact that any particle clusters that may have formed were ground as the blending process progressed. This positive result is an indication that the problems of agglomeration encountered in liquid-state processes could be averted by using solid-state techniques.

\section{0 vol. \% SiC}

The micrographs in Figure 3 show that all three 10\% SiC batches contained spherical 2124-Al alloy particles surrounded by small, irregularly shaped SiC particles. As only a small amount of the SiC particles coated the 2124-Al alloy particles and a large amount of the SiC particles were loose, it can be inferred that the SiC powder did not blend fully with the aluminium alloy powder. This poor blending was attributed to poor surface interaction between $\mathrm{SiC}$ and the 2124-Al alloy particles.

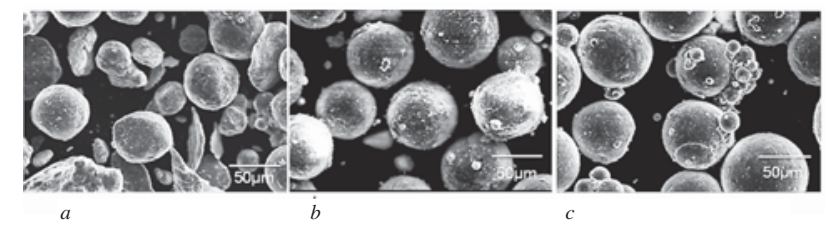

Figure 1-MMNC blended powders with 5 vol. $\% \mathrm{Al}_{2} \mathrm{O}_{3}$ from (a) batch 1, (b) batch 2 and (c) batch 3

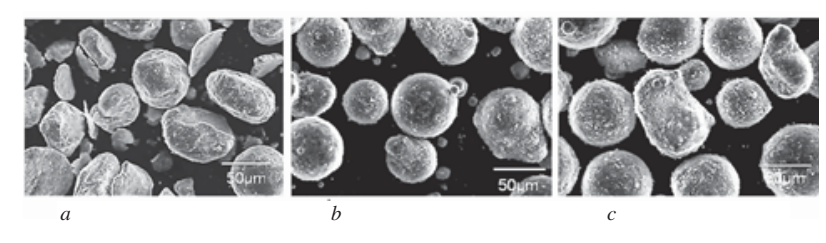

Figure 2-MMNC blended powders with $10 \mathrm{vol} . \% \mathrm{Al}_{2} \mathrm{O}_{3}$ from (a) batch 1, (b) batch 2 and (c) batch 3 


\section{Deformation behaviour of aluminium low-micron MMCs and MMNCs}

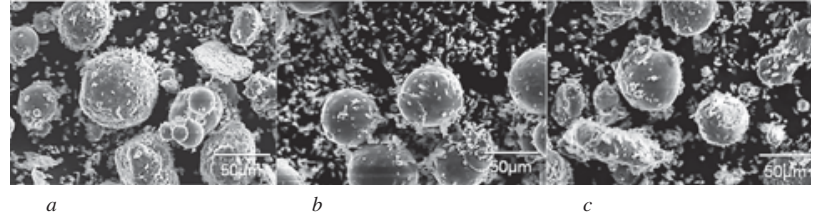

Figure 3-MMC blended powders with 10 vol.\% SiC from (a) batch 1, (b) batch 2 and (c) batch 3

\section{Powder characterization}

The mode of the particle size distribution (PSD) for the unreinforced 2124-Al alloy powder was $74 \mu \mathrm{m}$. Figure $4 \mathrm{a}$ shows that the addition of $5 \mathrm{vol} . \% \mathrm{Al}_{2} \mathrm{O}_{3}$ to the 2124-Al powder caused no difference to the shape or mode of the PSD curves for batches 2 and 3 (mode of $74 \mu \mathrm{m}$ ), but the mode of batch 1 was $62.23 \mu \mathrm{m}$, indicating breakage of some 2124-Al particles. There was less scatter with $10 \mathrm{vol} . \% \mathrm{Al}_{2} \mathrm{O}_{3}$ addition (Figure 4b) with PSD modes of batches 2 and 3 between 62 and $74 \mu \mathrm{m}$ and the mode of batch 1 at $62 \mu \mathrm{m}$.

The 2124-Al/SiC powder batches had bimodal size distributions (Figure 5), shown by two peaks on the PSD curves, with the major peaks very close to that of the pure 2124-Al powder. The minor peaks at approximately $5.5 \mu \mathrm{m}$ (Figures $5 \mathrm{a}$ and $5 \mathrm{~b}$ ) correspond with loose SiC particles that did not adhere to the 2124-Al powder. However, there was no minor peak for $10 \%$ Sic batch 1, as the sizes ranged from 2.75 to $37 \mu \mathrm{m}$, showing agglomeration of the SiC particles. All batches with $10 \%$ and $15 \%$ SiC powders had major peak modes of 62 to $74 \mu \mathrm{m}$, showing slight attrition of the 2124Al powder particles. The bimodal nature of the SiC-added PSD curves show a much lower adherence of SiC to the 2124-Al particles (Figure 5) than the $\mathrm{Al}_{2} \mathrm{O}_{3}$-added powder particles (Figure 4), indicating poorer blending behaviour of SiC.

\section{Compaction}

During cold compaction, the green compacts of the unreinforced and blended powders fractured into thin, nearly horizontal slices, as shown in Figure 6. This was attributed to natural ageing of the 2124-Al alloy powder due to long-term storage (Nazarenko et al., 2014). The powders were then exposed to an over-ageing heat treatment at $350^{\circ} \mathrm{C}$ for 2 hours in order to reverse the effects of ageing. Figure 7 shows a green compact that was successfully compacted using the over-aged powder.

Optical microscopy of the green compact (Figure 7) revealed a non-uniform density distribution in the uniaxial green compact, with high density at the surface (Figure 8a) and low density at the core (Figure 8b). German (1994) showed how density varies in green compacts from both single- and double-action pressing (Figure 9). In the current work, double-action pressing was used. From Figure 9 it can be observed that green compacts produced from doubleaction pressing have lower densities at the mid-height surface (Hofmann and Bowen, 2011).

Pressure gradients, caused by the friction between the powder and the die walls, lead to non-uniform density distribution in green compacts (Glass and Ewsuk, 1995). The frictional force opposes the applied force and decreases the amount of pressure transmitted to the powder for consolidation (Turenne et al., 1999), so high pressures result in high green densities (Tiwari, Rajput and Srivastava 2012). Thus the lower densification observed at the core of the sample (Figure 8b) is an indication of a non-uniform density distribution in the sample.

The technique of over-ageing the powders before cold compaction worked for the unreinforced and reinforced powders, except for the powder reinforced with $10 \mathrm{vol} . \%$ $\mathrm{Al}_{2} \mathrm{O}_{3}$. The poor compressibility of the $2124-\mathrm{Al} / 10 \% \mathrm{Al}_{2} \mathrm{O}_{3}$

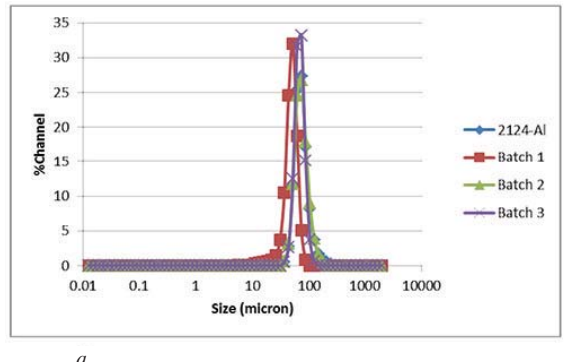

Figure 4-PSD curves for 2124-Al with (a) $5 \% \mathrm{Al}_{2} \mathrm{O}_{3}$ and (b) $10 \% \mathrm{Al}_{2} \mathrm{O}_{3}$ powders

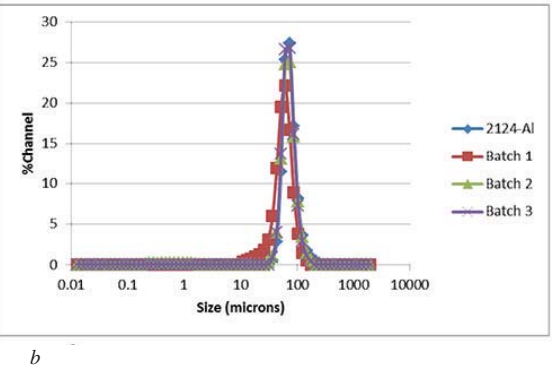

$b$

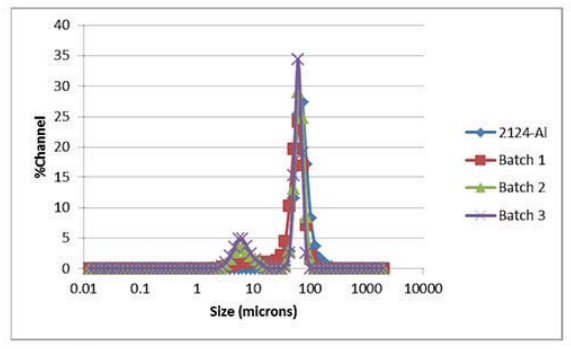

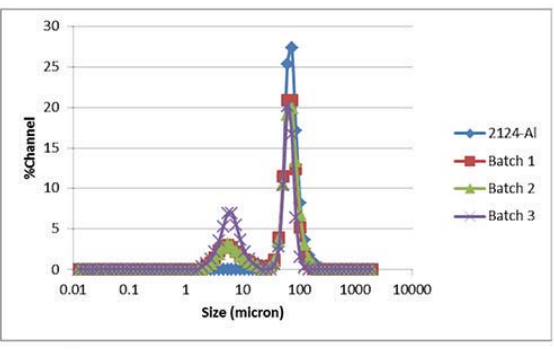

$b$ 


\section{Deformation behaviour of aluminium low-micron MMCs and MMNCs}

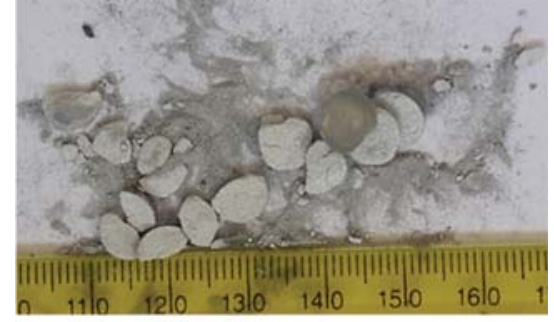

Figure 6-Fractured green compact

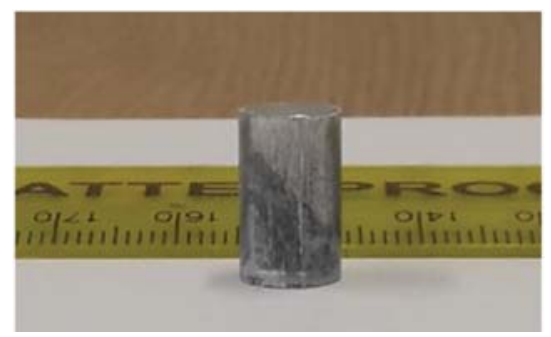

Figure 7-Green compact successfully compacted from over-aged powder
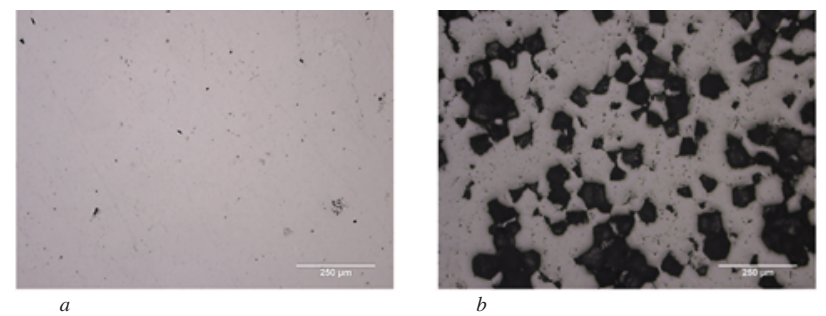

Figure 8-Difference in consolidation at (a) surface and (b) core of a green compact (shown in Figure 7) made with over-aged powder
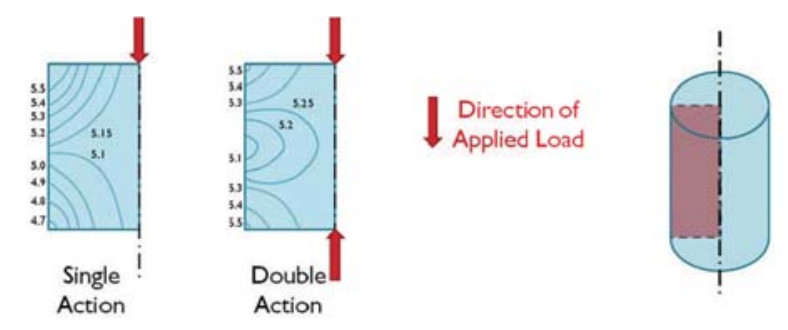

Figure 9-Diagrams illustrating non-uniform density distribution in green compacts produced by single- and double-action pressing (German, 1994, redrawn by Selig, 2012)

powder could have been due to the higher amount of $\mathrm{Al}_{2} \mathrm{O}_{3}$ on the surface of the 2124-Al particles, thus limiting the effect of over-ageing and preventing plastic deformation and bonding. $\mathrm{Al}_{2} \mathrm{O}_{3}$ has a high heat resistance, so the $\mathrm{Al}_{2} \mathrm{O}_{3}$ coating could have acted as a barrier to heat transfer thus limiting the effect of over-ageing, which meant that the hardness of the $2124-\mathrm{Al} / 10 \% \mathrm{Al}_{2} \mathrm{O}_{3}$ powder was not changed dramatically by the over-ageing process (Pham, Maruoka and Nanko, 2016). The presence of more $\mathrm{Al}_{2} \mathrm{O}_{3}$ particles on the aluminium alloy particle surfaces, due to a higher vol. $\% \mathrm{Al}_{2} \mathrm{O}_{3}$ added, could have increased the hardness of the reinforced powder even further, since $\mathrm{Al}_{2} \mathrm{O}_{3}$ has a higher hardness than the $\mathrm{Al}$ alloy (Auerkari, 1996).

Poor consolidation and very little plastic deformation or bonding occurred in the $2124-\mathrm{Al} / 10 \% \mathrm{Al}_{2} \mathrm{O}_{3}$ composite, as shown in the polished section in Figure 10. Figure 10 shows that there are nano- $\mathrm{Al}_{2} \mathrm{O}_{3}$ particles situated on the $\mathrm{Al}$ alloy grain boundaries. The micrograph supports the notion that plastic deformation and bonding were limited by the presence of $\mathrm{Al}_{2} \mathrm{O}_{3}$ particles on $\mathrm{Al}$ alloy particle surfaces.

Micrographs of the compacted $2124-\mathrm{Al} / 10 \% \mathrm{SiC}$ powder are shown in Figures 11(a) and 11(b). These images show that consolidation was achieved by localized deformation at grain boundaries where there were few or no SiC particles. The same result was obtained for $2124-\mathrm{Al} / 15 \% \mathrm{SiC}$ composite (not shown). This shows that in composite powders where reinforcing particles have settled on grain boundaries, consolidation is achieved by localized deformation at small contact points between matrix grains.

\section{Uniaxial compression tests}

The uniaxial compression tests performed in the Gleeble $3500^{\circledR}$ at ambient temperature were unsuccessful, as the green compacts fractured immediately under the compressive load, as shown in Figure 12.

Engineering stress-strain curves from uniaxial compression tests performed at ambient temperature (Figure 13) show the deformation behaviour of 2124-Al alloy, 2124-Al with $5 \% \mathrm{Al}_{2} \mathrm{O}_{3}$ and $2124-\mathrm{Al}$ with $10 \% \mathrm{SiC}$ at ambient temperature. The three materials behaved in a similar manner during deformation since their stress-strain

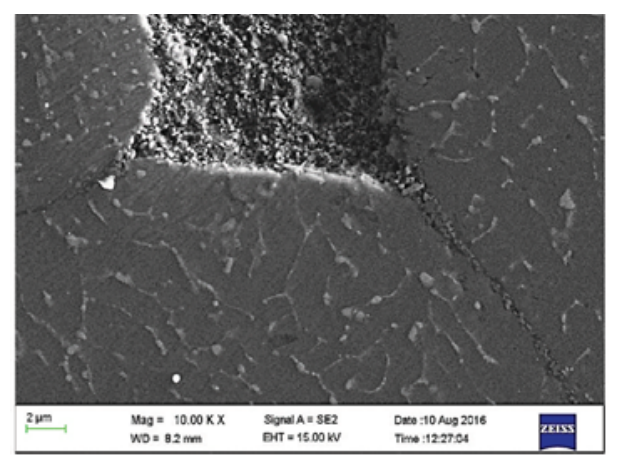

Figure 10-SEM micrograph showing polished section of MMNC green compact with 10 vol. $\% \mathrm{Al}_{2} \mathrm{O}_{3}$
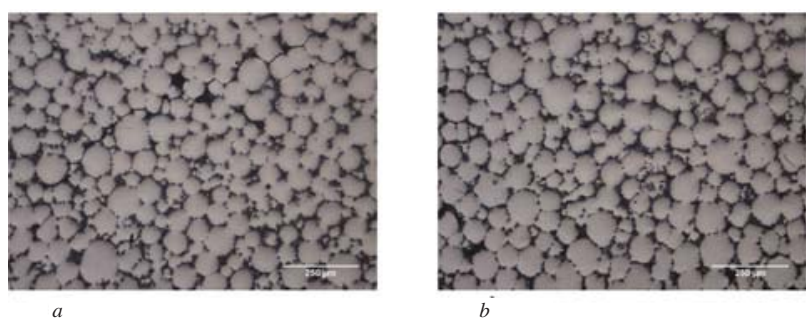

Figure 11-Optical micrographs showing consolidation at (a) surface and (b) core of a MMC green compact with $10 \mathrm{vol}$. $\%$ SiC produced from over-aged powder 


\section{Deformation behaviour of aluminium low-micron MMCs and MMNCs}

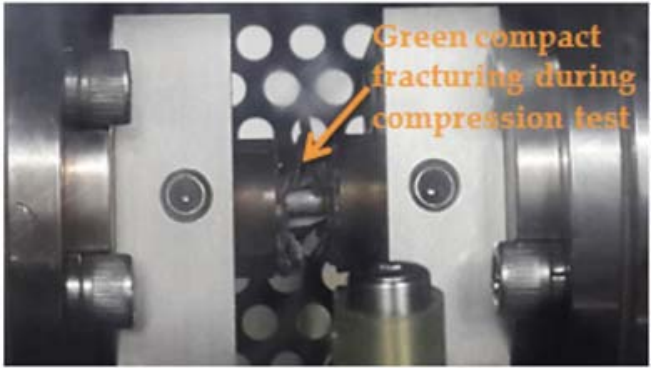

Figure 12-Image showing a green compact fracturing during compression test at ambient temperature

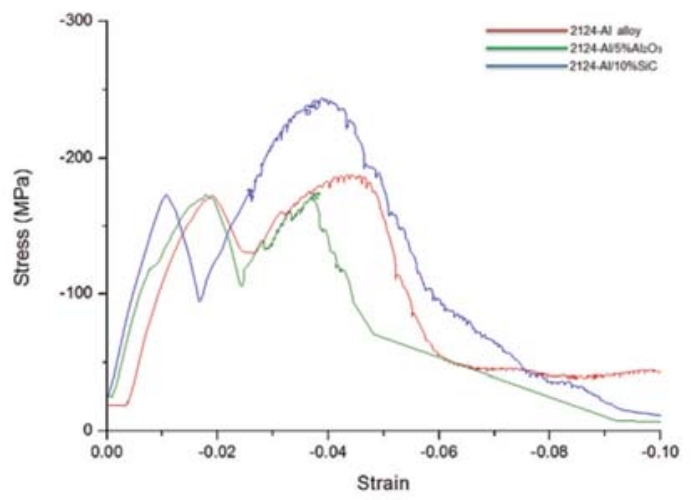

Figure 13-Engineering stress-strain curves showing deformation behaviour of 2124-Al alloy, and 2124-Al with $5 \% \mathrm{Al}_{2} \mathrm{O}_{3}$ and $10 \% \mathrm{SiC}$ green compacts at ambient temperature $(6$ minutes soak time and $0.01 \mathrm{~s}^{-1}$ strain rate)

curves follow the same trend. The compressive fracture stresses of the 2124-Al, 10\% SiC MMC and 5\% $\mathrm{Al}_{2} \mathrm{O}_{3}$ MMNC green compacts were similar at approximately $170 \mathrm{MPa}$. The peculiar shape of the stress-strain curves shows that the green compacts initially compressed and elastically deformed to a stress of approximately $170 \mathrm{MPa}$ and then started to fracture as the plastic region was approached, leading to a sharp decrease in stress.

In initial testing at a programmed temperature of $280^{\circ} \mathrm{C}$, electrical resistance heating of the green compacts did not occur, which was attributed to the high electrical conductivity and low resistance of aluminium. High electrical conductivity resulted in poor heat generation because electrical resistance in the samples was low (Ozturk et al., 2016). It was presumed that the small sample size $(d=8 \mathrm{~mm}, h=12 \mathrm{~mm})$ also caused rapid heat loss .After further experimentation, the green compacts were heated successfully by using fibre optic wool and a conductive foil wrapped around the samples as insulation in order to retain heat.

The deformation behaviour of $2124-\mathrm{Al}$ with $5 \% \mathrm{Al}_{2} \mathrm{O}_{3}$, $10 \% \mathrm{SiC}$ and $15 \% \mathrm{SiC}$ at $280^{\circ} \mathrm{C}$ is shown in Figure 14 . The peaks of the curves represent the maximum flow stress. It is interesting to see that the $10 \% \mathrm{SiC}$ sample showed a higher flow stress $(200 \mathrm{MPa})$ than the $15 \% \mathrm{SiC}$ sample (170 MPa). This could be a result of improved consolidation during compaction of $2124-\mathrm{Al}$ with $10 \%$ SiC compared with $15 \%$ $\mathrm{SiC}$.
The higher temperature improved the shape of the compression curves, removing the sudden drop in stress after elastic deformation that was seen in the ambient temperature tests. This indicates that the deformation was more uniform, which can be attributed to improved plastic flow due to an increase in temperature (Osakada, 1997).

The soaking time was increased from 6 to 20 minutes for the MMC green compact with $10 \mathrm{vol} . \% \mathrm{SiC}$ to assess the effect of soaking time on deformation behaviour, as shown in Figure 15. The shape of the flow stress curve improved and it looks more like a standard compressive stress-strain curve. The various points and regions (elastic region, plastic region, maximum flow stress and final fracture point) on the curve can easily be identified. This shows that an increase in soaking time improved plastic flow in the material and improved the deformation behaviour.

Increasing the soaking time from 6 to 20 minutes decreased the maximum flow stress from 200 to approximately $170 \mathrm{MPa}$. Holding the sample at an elevated temperature for an increased time leads to more atoms gaining energy, thus the flow of particles in the material is improved (Arya et al., 2016). Deforming the material became easier and a lower load was required to deform the material. As the soaking time did have an effect on the deformation behaviour it should be carefully selected.

\section{Conclusions}

The deformation behaviour, at warm working temperatures, of green particle-reinforced aluminium composites produced

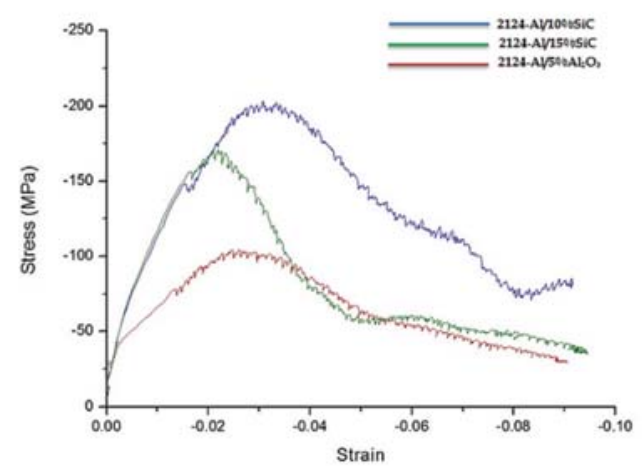

Figure 14-Engineering stress-strain curves showing deformation behaviour of $2124-\mathrm{Al}$ with $5 \% \mathrm{Al}_{2} \mathrm{O}_{3}, 10 \% \mathrm{SiC}$ and $15 \% \mathrm{SiC}$ at $280^{\circ} \mathrm{C}(6$ minutes soak time, $0.01 \mathrm{~s}^{-1}$ strain rate)

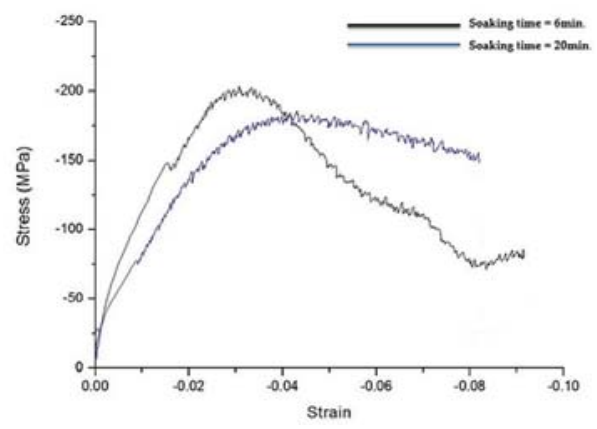

Figure 15-Engineering stress-strain curves showing the influence of soaking time (6 or 20 minutes) on deformation behaviour of MMC green compacts with $10 \mathrm{vol}$. $\% \mathrm{SiC}$ at $280^{\circ} \mathrm{C}$ 


\section{Deformation behaviour of aluminium low-micron MMCs and MMNCs}

by powder blending in a high-energy ball mill was investigated by performing uniaxial compression tests in a Gleeble $3500^{\circledR}$ thermomechanical simulator.

1. After blending, the morphology and size of the 2124$\mathrm{Al}$ powder and the distribution of the $\mathrm{SiC}$ or $\mathrm{Al}_{2} \mathrm{O}_{3}$ reinforcing phase on the aluminium alloy particles were consistent over three batches

2. A more uniform distribution of the reinforcement phase was achieved in 2124-Al composites with nano$\mathrm{Al}_{2} \mathrm{O}_{3}$ than with micro-SiC

3. Long-term storage of the age-hardenable aluminium alloy powders caused ageing, which results in a change in the powder characteristics such as hardness. Ageing was reversed by heat treatment of the unreinforced and blended powders into the over-aged condition

4. Electrical resistance heating of green compacts of aluminium alloy 2124, its MMC composites with SiC and $\mathrm{MMNC}$ composites with $\mathrm{Al}_{2} \mathrm{O}_{3}$ can be improved by insulating the samples with fibre optic wool and a conductive foil

5. The deformation of the 2124-Al alloy, $10 \% \mathrm{SiC} M M C$ and $5 \% \mathrm{Al}_{2} \mathrm{O}_{3} \mathrm{MMNC}$ green compacts was poor at ambient temperature and the compacts had similar compressive fracture stresses. Improved deformation behaviour was observed at $280^{\circ} \mathrm{C}$ and the $\mathrm{MMC}$ with $10 \% \mathrm{SiC}$ had the highest maximum flow stress (approx. $200 \mathrm{MPa}$ )

6. Increasing the soaking time at $280^{\circ} \mathrm{C}$ from 6 to 20 minutes decreased the maximum flow stress from $200 \mathrm{MPa}$ to approximately $170 \mathrm{MPa}$ and improved the compressive deformation behaviour of the 2124$\mathrm{Al} / 10 \% \mathrm{SiC}$ green compact.

\section{References}

Arya, V., PADAP, A.K., KumAr, M. and HiwarKAr, A.D. 2016. Mechanical properties and elcetroconductivity of aluminum alloys processed using uniaxial compression. Proceedings of the 3rd International Conference on Science, Technology and Management (ICSTM-16), New Dehli. pp. 749-754. http://doi.org/978-81-932074-0-6

AUERKARI, P. 1996. Mechanical and physical properties of engineering alumina ceramics. Mechanical and physical properties of engineering alumina ceramics. Research Notes 1792. VTT Technical Research Centre of Finland.

Borgonovo, C. and ApeliAn, D. 2011. Manufacture of aluminum nanocomposites: a critical review. Materials Science Forum, vol. 678. pp. 1-22. http://doi.org/10.4028/www.scientific.net/MSF.678.1

CASATI, R. and Vedani, M. 2014. Metal matrix composites reinforced by nanoparticles-a review. Metals, vol. 4, no. 1. pp. 65-83. http://doi.org/10.3390/met4010065

CAVAliere, P. 2002. Hot and warm forming of 2618 aluminium alloy. Journal of Light Metals, vol. 2, no. 4. pp. 247-252. http://doi.org/10.1016/S1471 5317(03)00008-7

FERRY, M. 2005. Discontinuously reinforced metal matrix composites. The Deformation and Processing of Structural Materials. Guo, X.Z. (ed.), Woodhead Publishing, UK. p. 203. https://books.google.co.za/books? $\mathrm{hl}=\mathrm{en} \& \mathrm{lr}=\& \mathrm{id}=\mathrm{QbukAgAAQBAJ} \& \mathrm{oi}=\mathrm{fn} d \& \mathrm{pg}=\mathrm{PA} 203 \& \mathrm{dq}=$ discontinuously+reinforced+metal+matrix+composite\&ots=LqdU3ZDaei\&sig=Cseon oY467mV9ggRLwo-v5CScyw\#v=onepage $\& \mathrm{q}=$ discontinuously reinforced metal matrix composite $\& \mathrm{f}=$ false

German, R.M. 1994. Powder Metallurgy Science. (2nd edn). Metal Powder Industries Federation, New Jersey.
GLAss, S.J. and Ewsuk, K.G. 1995. Ceramic powder compaction. American Ceramic Society International Symposium on Manufacturing Practices and Technology. http://doi.org/10.1557/S0883769400034709

HiRIANIAH, C.S.R.A., HaRishanad, K.S. and NoRonHA, N.P. 2012. A review on hot extrusion of metal matrix composites. RESEARCH INVENTY: International Journal of Engineering and Science, vol. 1, no. 10. pp. 30-35.

Hofmann, H. and Bowen, P. 2011. Powder Technology. Part II: Compaction. Laboratory of Powder Technology, École Polytechnique Féderalé de Lausanne.

JENSRUD, O. 1998. Warm-deformation and the age hardening response in two aluminium alloys. Advanced Light Alloys and Composites. Springer Dordrecht. pp. 415-420.http://doi.org/10.1007/978-94-015-9068-6_54

Liang, X., Earthman, J.C., Wolfenstine, J. and Lavernia, E.J. 1992. A comparison of techniques for determining the volume fraction of particulates in metal matrix composites. Materials Characterization, vol. 28, no. 4. pp. 173-178. http://doi.org/10.1016/1044-5803(92)90079-W

MAzEn, A.A. and EMARA, M.M. 2004. Effect of particle cracking on the strength and ductility of Al-SiCp powder metallurgy metal matrix composites. Journal of Materials Engineering and Performance, vol. 13, no. 1. pp. 39-46. http://doi.org/10.1361/10599490417579

NAZARENKo, O.B., Amelkovich, Y.A. and SECHIN, A.I. 2014. Characterization of aluminum nanopowders after long-term storage. Applied Surface Science, vol. 321. pp. 475-480. http://doi.org/10.1016/j.apsusc.2014.10.034

OsAKADA, K. 1997. Effects of strain rate and temperature in forming processes of metals. Le Journal de Physique IV, vol. 7. pp. 37-44. http://doi.org/10.1051/jp4:1997302

Ozturk, F., Ece, R.E., Polat, N., Koksal, A., Evis, Z. and Sheikh-Ahmad, J.Y. 2016. Application of electric resistance heating method on titanium hot forming at industrial scale. Arabian Journal for Science and Engineering. http://doi.org/10.1007/s13369-016-2159-6

Pham, H.V., MARUOKA, D. and NANKo, M. 2016. Influences of $\mathrm{Al}_{2} \mathrm{O}_{3}$ grain size on high-temperature oxidation of nano- $\mathrm{Ni} / \mathrm{Al}_{2} \mathrm{O}_{3}$ composites. Journal of Asian Ceramic Societies, vol. 4, no. 1. pp. 120-123. http://doi.org/10.1016/j.jascer.2016.01.003

RAJPUT, R.K. 2007. Metal forming processes. A Textbook of Manufacturing Technology: Manufacturing Processes (1st edn). Laxmi, New Dehli. pp. 142-143. https://books.google.co.za/books?id=6wFuw6wufTMC\&pg =PA140\&lpg=PA140\&dq=journals+on+disadvantages+of+hot+working+m etals \&source=bl\&ots=7F-q942-wt\&sig=9Ioky-tAxuqmF9XBscLgJLcy RGc\&hl=en\&sa=X\&ved=0ahUKEwiRybafuprNAhXhB8AKHZRjAOY4ChDo AQgbMAE\#v=onepage $\& q=$ journal

RaO, B.K., KHADAR, M.S.A. and SRINIVASAn, K. 1999. High temperature compression testing and determination of warm working temperature for commercial purity aluminium. Bulletin of Materials Science, vol. 22, no. 1. pp. 17-20. http://doi.org/10.1007/BF02745670

Saravanan, L. and Senthilvelan, T. 2015. Investigations on the hot workability characteristics and deformation mechanisms of aluminium alloy- $\mathrm{Al}_{2} \mathrm{O}_{3}$ nanocomposite. Materials \& Design, vol. 79. pp. 6-14 http://doi.org/10.1016/j.matdes.2015.04.024

SELIG, S.G. 2012. Finite element simulation of the compaction and springback of an aluminium powder metallurgy alloy. Dalhousie University.

Tiwari, S., RajPUT, P. and SRIVASTAVA, S. 2012. Densification behaviour in the fabrication of Al-Fe metal matrix composite using powder metallurgy route. ISRN Metallurgy, 2012, pp. 1-8. http://doi.org/10.5402/2012/195654

Turenne, S., Godere, C., Thomas, Y. and Mongeon, P.E. 1999. Evaluation of friction conditions in powder compaction for admixed and die wall lubrication. Powder Metallurgy, vol. 42, no. 3. pp. 263-268. http://doi.org/10.1179/003258999665611

Zhou, J., Druzdzel, A. and Duszczyк, J. 1999. The effect of extrusion parameters on the fretting wear resistance of Al-based composites produced via powder metallurgy. Journal of Materials Science, vol. 34, no. 20 . pp. 5089-5097. 